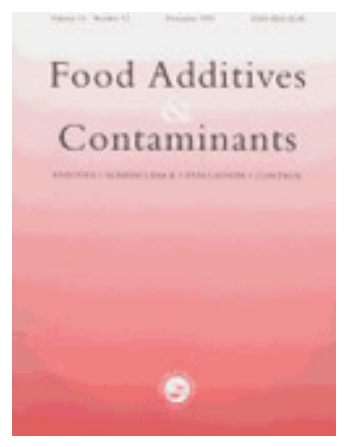

\title{
Carry-over of dioxins and PCBs from feed and soil to eggs at low contamination levels; Influence of mycotoxin binders on the carry-over from feed to eggs
}

\begin{tabular}{|r|l|}
\hline Journal: & Food Additives and Contaminants \\
\hline Manuscript ID: & TFAC-2005-176.R1 \\
\hline Manuscript Type: & Original Research Paper \\
\hline Author: & 11-Nov-2005 \\
\hline Complete List of Authors: & $\begin{array}{l}\text { Hoogenboom, Ron; RIKILT-Institute of Food Safety, Safety and } \\
\text { Health } \\
\text { Zeilmaker, Marco; RIVM } \\
\text { Traag, Wim; RIKILT-Institute of Food Safety } \\
\text { Kan, Kees; Animal Science Group of Wageningen UR, Animal } \\
\text { Husbandry } \\
\text { van Eijkeren, Jan; RIVM }\end{array}$ \\
\hline Methods/Techniques: & Regulations, Toxicology - pharmokinetics \\
\hline Additives/Contaminants: & Dioxins, PCBs \\
\hline Food Types: & Animal, Eggs, Animal feed \\
\hline \multicolumn{2}{|l}{} \\
\hline
\end{tabular}

\section{SCHOLARONE" Manuscripts}




\section{7 contamination levels - Influence of mycotoxin binders on the}

8 carry-over from feed to eggs

9

$25 *$ To whom correspondence should be addressed. e-mail : ron.hoogenboom@wur.nl, tel. +31 $26 \quad 317475623$

1 RIKILT Institute of Food Safety, Bornsesteeg 45, 6708PD Wageningen, The Netherlands

82 Animal Sciences Group of Wageningen UR, Division Animal Husbandry, P.O. Box 65, 8200 AB Lelystad,

19 The Netherlands

3 RIVM National Institute of Public Health and the Environment, P.O.Box 1, 3720 BA, Bilthoven, The 


\section{Abstract}

28 Laying hens were fed with compound feed containing six different levels of dioxins, dioxin29 like PCBs and indicator PCBs for a period of 56 days. This was followed by a period of 56 30 days on clean feed. Dioxin levels in feed varied from background levels to three times the 31 current EU tolerance limit of $0.75 \mathrm{ng} \mathrm{TEQ} / \mathrm{kg}$. At all dose levels a rapid increase was 32 observed in the dioxin levels in eggs.. There was a clear linear dose-response relationship 33 between the dioxin levels in eggs and feed. The feed containing $0.4 \mathrm{ng}$ TEQ dioxins per $\mathrm{kg}$ 34 resulted in egg levels just above the EU limit of $3 \mathrm{pg}$ TEQ/g fat. Dioxin-like and indicator 35 PCB residues followed a pattern very similar to that of dioxins. Exposure to the highest 36 indicator PCB level of $32 \mu \mathrm{g} / \mathrm{kg}$ resulted in egg levels around $300 \mathrm{ng} / \mathrm{g}$ fat.

37 Exposure to dioxins through contaminated soil, mixed at $10 \%$ into the feed, resulted in a 38 similar carry-over as from feed. Mycotoxin binders, mixed at $0.5 \%$ into the feed, had little 39 effect on the carry-over of dioxins from the feed to the egg.

40 It can be concluded that consumption of feed or soil with even moderate levels of dioxins 41 and dioxin-like PCBs rapidly results in increased levels in eggs. The current EU dioxin limit 42 for feed cannot guarantee egg dioxin levels below the EU-limit.

44 Keywords: dioxins, PCBs, carry-over, chickens, eggs, feed, soil 


\section{Introduction}

Incidents with residues of PCBs and dioxins have shown that these compounds pose a major threat to the quality of edible products derived from food producing animals. As the exposure of part of the populations in Western countries still exceeds the exposure limits set by e.g. the Scientific Committee on Food (SCF 2001), the EU has developed a strategy for further reducing the exposure to dioxins and dioxin-like PCBs. This includes the establishment of residue limits for dioxins in food (EC 2001) and feed (EC 2002).

Since the dioxin crisis in 1999 in Belgium, the Dutch government established a number of monitoring programmes for dioxins aiming at the early detection of contaminated feed and food and subsequently the revelation and elimination of novel sources of dioxins. In 2001, over 300 samples of animal origen were screened in the DR CALUX-assay and if suspected positive for dioxins, analysed by HRGC/HRMS. In one case, eggs obtained from a small farm with free-range hens were shown to contain dioxin levels above the then existing Dutch limit of $5 \mathrm{pg}$ TEQ/g fat (Traag et al. 2002). This initial observation was followed by a focussed action on these types of eggs and showed a clear elevation in dioxin levels in eggs from freerange hens, in particular those from farms producing eggs according to strict organic standards. This was confirmed in a survey by The Dutch Food Inspection Service, showing that eggs from six out of 68 farms would exceed the new EU dioxin limit for eggs of $3 \mathrm{pg}$ TEQ/g (as of July 2003), and three exceeded the then existing limit of $5 \mathrm{pg}$ TEQ/g (De Vries, 2002). In addition some of the samples contained high levels of dioxin-like PCBs, with a highest total TEQ level of $15 \mathrm{pg}$ TEQ/g fat. Follow-up studies were performed during the winter at the first farm, and the levels in eggs from hens that were kept inside, strongly suggested that the source of the contamination was not the feed, but the outdoor environment (unpublished). Similar has been observed in other studies, but in these cases the soil was clearly contaminated with dioxins (Stephens et al. 1990, 1994, 1995, Schuler et al. 1997, 
70 Lovett et al. 1998, Harnly et al. 2000, Petreas et al. 2001, Air et al. 2002, Pussemier et al. 71 2004). Another study was performed in the autumn of 2003, when a large number of farms 72 producing organic eggs were visited and investigated for possible sources of dioxins and 73 factors that may contribute to the exposure of hens to dioxins (Brandsma et al. 2004). This 74 study again showed that most eggs would comply with the current dioxin limit of $3 \mathrm{pg}$ TEQ/g 75 fat, but that $13 \%$ of the eggs, produced on $26 \%$ of the farms would not be in compliance with 76 this limit.

77 In July 2003, new EU limits for dioxins in food and feed became official, including limits 78 for eggs and feed, being respectively $3 \mathrm{pg}$ TEQ/g fat and $0.75 \mathrm{ng}$ TEQ/kg feed (EC 2001, 79 2002). Eggs from free-ranging hens were excluded from these limits until 1-1-2004, later 80 extended to 1-1-2005. At the same time, studies were started to investigate the carry-over of 81 dioxins and PCBs from feed and soil to eggs at relatively low levels, and to investigate 82 possible ways for reducing the exposure and carry-over. The current paper describes a 83 controlled study on the relationship between dioxin and PCB levels in eggs and feed (Study 84 I), as well as soil (Study II). Contrary to previous studies 6 different levels in feed were used 85 in a range around the current and proposed EU-limits for dioxins and dioxin-like PCBs. In 86 addition we studied the depletion of these contaminants, which is relevant for risk 87 management purposes in cases of crisis situations. As a potential tool to decrease the carry88 over to eggs we also tested the effects of so-called mycotoxin binders on the carry-over of 89 dioxins and PCBs (Study III). The results of the studies were used to develop a mathematical 90 model based on the physiology of the laying hen, that can be used for predicting the levels in 91 eggs resulting from a certain feed contamination, and the effect of certain variables on this 92 relationship (Van Eijkeren et al. 2005). 
93

94

95

96

97

98

99

100

101

102

103

104

105

106

107

108

109

110

111

112

113

114

115

116

117

\section{Materials and methods}

\section{Preparation of feed}

\section{Preparation of feed for Study I: relation between levels in feed and eggs}

Feed was prepared with soy oil spiked with the different dioxin and PCB congeners. The composition of the feed is given in Table 1. A blanc oil, obtained from Nutreco (Boxmeer, The Netherlands) was analysed by both CALUX and by GC/MS and shown to be low in dioxin-like compounds. Subsequently, a stock solution of contaminated oil was prepared with about 7500 pg TEQ/g of dioxins and dioxin-like PCBs. An aliquot of 200-gram oil was mixed with the following PCB stock solutions: $7.5 \mathrm{ml}$ PCB 105 at $100 \mathrm{ng} / \mathrm{ml}, 15 \mathrm{ml}$ PCB 118 at 100 ng/ml, $1.2 \mathrm{ml}$ PCB 156 at $100 \mathrm{ng} / \mathrm{ml}, 7.5 \mathrm{ml}$ PCB 28 at $100 \mathrm{ng} / \mathrm{ml}, 15 \mathrm{ml}$ PCB 52 at 100 ng/ml, $30 \mathrm{ml} \mathrm{PCB} 101$ at $100 \mathrm{ng} / \mathrm{ml}, 30 \mathrm{ml} \mathrm{PCB} 138$ at $100 \mathrm{ng} / \mathrm{ml}, 30 \mathrm{ml}$ PCB 153 at 100 $\mathrm{ng} / \mathrm{ml}$ and $15 \mathrm{ml} \mathrm{PCB} 180$ at $100 \mathrm{ng} / \mathrm{ml}$. The organic solvent (nonane) was removed under vacuum. Subsequently the following standard mixtures were added: $44 \mu \mathrm{CIL}$ EDF-4096 dioxins (tetra's $2.5 \mathrm{ng} / \mu \mathrm{l}$, penta's, hexa's and hepta's $6.25 \mathrm{ng} / \mu \mathrm{l}$ and octa's $12.5 \mathrm{ng} / \mu \mathrm{l}$ ), $408 \mu \mathrm{l}$ CIL EC-4986 non-ortho PCBs $(10 \mu \mathrm{g} / \mathrm{ml})$ and $785 \mu \mathrm{CIL}$ EC-4987 mono-ortho PCBs (10 $\mu \mathrm{g} / \mathrm{ml})$. The organic solvent again was removed under vacuum $\left(1 \mathrm{hr}, 63^{\circ} \mathrm{C}\right)$.

The 200 gram oil was first diluted to 1500 gram, and subsequently diluted for incorporation into the different feeds, as follows: 30 gram +1470 gram blank oil (b used for feed B), 60 gram +1440 gram blank oil (c used for feed C), 265 gram +3237 gram blank oil (d used for feed D), 685 gram +3882 gram blank oil (e used for feed E), and 420 gram +980 gram blank oil (f used for feed F).

Analysis of oil b by GC/MS showed a total TEQ content of $20 \mathrm{pg}$ TEQ/g, with a contribution of $11 \mathrm{pg}$ TEQ/g for dioxins, $5.3 \mathrm{pg}$ TEQ/g for non-ortho PCBs and $3.7 \mathrm{pg}$ TEQ/g 
118 for mono-ortho PCBs. The blank oil contained a total TEQ content of $0.4 \mathrm{pg}$ TEQ/g fat

119 (upperbound). Based on these results the Nutreco feed mill in Heyen, The Netherlands, 120 prepared the feeds with $0.95 \%$ of oils (b) to (f), and the blank oil a in the following quantities:

121290 and $650 \mathrm{~kg}$ blank feed (prepared in 2 batches), $110 \mathrm{~kg}$ of feeds B, C, D and F, and $400 \mathrm{~kg}$

122 of feed E. Table 2 shows the analysed dioxin content of the different feeds

123

124 Preparation of feed for Study II: relation between levels in soil and eggs

125 Aim of this study was to assess the bioavailability of dioxins from contaminated soil.

126 Therefore, feeds were prepared by mixing the blank feed with $10 \%$ of soil collected from two 127 chicken farms with elevated dioxin and dioxin-like PCB levels in eggs. The soils had been 128 analysed previously showing dioxin levels of $5.88 \mathrm{ng} \mathrm{TEQ} / \mathrm{kg}$ (soil A) and $1.94 \mathrm{ng} \mathrm{TEQ} / \mathrm{kg}$ 129 (soil B). Pooled egg samples collected at the same time at these farms were shown to contain 130 dioxin levels of 1.0 and $7.3 \mathrm{pg}$ TEQ/g fat. An additional feed was prepared as a control, by 131 mixing feed E (study I) with $10 \%$ of clean sand.

133 Preparation of feed for Study III: effect of binders on carry-over from feed to eggs

134 Aim of this study was to assess whether or not binders would influence the bioavailability of 135 dioxins and PCBs in feed. A number of different binders were obtained for this study from the 136 producers. These materials were claimed to prevent the absorption of mycotoxins and as such 137 might be potential candidates for reducing the absorption of dioxins as well. The materials 138 were first screened by DR CALUX ${ }^{\circledR}$ and analysed by GC/MS, and shown not to contain 139 elevated dioxins and PCBs. The following feeds were prepared: feed E mixed with $0.5 \%$ Exal $140 \mathrm{H}$ (Tessenderlo, Madrid, Spain), feed E mixed with 0.5\% MycoAd A-Z (Jadis, Schiedam, The 141 Netherlands), and feed E mixed with $0.5 \%$ Klinofeed (Unipoint, Truttikon, Switzerland). The 142 level of the binders was based on the recommendations of the providers. 


\section{Animal studies}

145 Study I

146 Hens (Bovans Gold line, age about 45 weeks at the start) were housed in a three-tier battery 147 with 3-4 hens per cage. The different groups contained 12, 12, 12, 13, 26 and 13 animals 148 respectively. After an adaptation period on blank feed for 1 week, hens were fed with the 149 different feeds A to F for 56 days, followed by another 56 days on blank feed A. During the 150 whole 112-day period eggs were collected and pooled per day per feeding group. On days 56 151 and 112, at least five hens from each group were slaughtered and abdominal fat, livers and the 152 ovaries collected. The group fed with feed E was larger allowing the collection of tissues of 153 another five animals on days 10 and 28.

Study II and III

156 Hens (ISA Brown Warren, age about 25 weeks at the start) were housed in a three-tier battery 157 with 2-3 hens per cage. The seven groups of 5 animals followed an adaptation period of one 158 week on clean feed, and then were fed with the different feeds for 32 days. During the whole 159 32-day period eggs were collected and pooled per day per feeding group. On day 32 the hens 160 from each group were slaughtered and abdominal fat, livers and the ovaries collected.

\section{Analysis of dioxins and dioxin-like PCBs}

163 Levels of dioxins, non-ortho and mono-ortho PCBs were determined by high resolution

164 GC/MS, basically as described by Tuinstra et al. (1994). Eggs and ovaries were freeze-dried 165 and subsequently fat was extracted using Accelerated Solvent Extraction (ASE). Abdominal fat 166 was melted in an oven at $70^{\circ} \mathrm{C}$. After extraction or sample pre-treatment ${ }^{13} \mathrm{C}$ labeled dioxins and 167 dioxin-like PCBs were added to the fat phase of the samples. Feed samples were extracted with 
168 ethyl acetate or, when minerals or soil was added to the feed (study II and III), with toluene using

169 ASE. Prior to extraction ${ }^{13} \mathrm{C}$ labeled dioxins and dioxin-like PCBs were added to the feed 170 samples. Separation between dioxins and fat was carried out using gel permeation 171 chromatography. The system consisted of an HPLC pump (Gilson, model 305, an autosampler 172 (Gilson, model 231) equipped to inject 12,5 $\mathrm{ml}$ of sample solution, and a fraction collector 173 (Gilson, model 202) adapted to collect $300 \mathrm{ml}$ fractions using $500 \mathrm{ml}$ glass collection flasks. The 174 glass GPC column (Spectrum) $(60 \times 2.5 \mathrm{~cm})$ was packed with Biobeads SX 3. After an 175 additional clean up with activated $\mathrm{Al}_{2} \mathrm{O}_{3}$, separation between planar compounds (dioxins and 176 non-ortho PCBs) and non-planar compounds like other PCBs was carried out with porous 177 graphitised carbon. The alumina (basic) clean-up was performed with an automatic sample 178 preparation system using solid phase extraction columns (ASPEC, Gilson). The columns were 179 packed with 1 gram deactivated alumina (7\% water) shortly before use. Porous graphitised 180 carbon clean up was performed using an HPLC system consisting of an HPLC pump (Gilson 181 model 205), a column switching device (Gilson, valvemate), a solvent switching device (Gilson, 182 valvemate), an autosampler (Gilson model 231), equipped with a $5 \mathrm{ml}$ loop and a fraction 183 collector (Gilson model 202) adapted to collect $100 \mathrm{ml}$ fractions. The column used was 184 Hypercarb (100 X $4.6 \mathrm{~mm}$ ) (Shandon). The final extract with planar compounds was concen185 trated to $10 \mu \mathrm{l}$ and the extract containing the non-planar PCBs to $200 \mu 1$. Both extracts were 186 analysed with gas chromato-graphy-high-resolution-mass spectrometry (HRGC-HRMS) 187 (Autospec, Micromass). The mass spectrometric method to determine the tetra through octa 188 dioxins is based on United States Environmental Protection Agency protocols. Included in the 189 analysis is a standard QA programme e.g. determination of recovery of internal standards, 190 accuracy of spiked samples and blanks. Non-detectable congeners were quantified at the limit of 191 detection (upperbound). Absolute levels were transfered to TEQ levels using the TEF values 192 described by Van den Berg et al. (1998). 
193 Analysis of indicator PCBs

194 The seven indicator PCBs $(28,52,101,118,138,153$ and 180) were analysed by GC/MS 195 following on-line clean-up over a silica HPLC column using a large volume injector (LVI). In 196 short, $200 \mathrm{mg}$ of the homogenised fat sample is mixed with $800 \mu \mathrm{l}$ of the internal standard 197 solution of ${ }^{13}$ C PCB 118 and PCB 198 (6.25 ng/ml). Subsequently, $50 \mu 1$ is injected onto the 198 silica column and after elution of the fat with hexane, the direction of the flow is switched to 199 back-flush and the column is cleaned with $3 \mathrm{ml}$ dichloromethane. The PCB containing 200 fraction (approximately $1 \mathrm{ml}$ ) is directly transferred to the gas chromatograph, which is 201 provided with an LVI. In the LVI the large amount of solvent was separated from the 202 compounds of interest by an uncoated retention gap of 10 meters, which ends up in a retaining 203 column of 1-meter coated with a non-polar phase. The temperature of the LVI, located in the 204 oven of the $\mathrm{GC}$, is slightly $\left(80^{\circ} \mathrm{C}\right)$ above the boiling point of the mobile phase. Hexane is 205 evaporated slowly and blown off via the Solvent Vapour Exit (SVE) while the PCB's are 206 retained on the 1-meter retaining column. After a specific time the majority of the solvent was 207 evaporated, the SVE closed and the temperature of the oven was raised in order to start 208 chromatography. Detection was done by mass-spectrometry with a bench top system in 209 Selected Ion Mode (SIM).

$211 \quad$ DR $\boldsymbol{C A L U} \boldsymbol{X}^{\circledR}$ analysis

212 The DR CALUX ${ }^{\circledR}$ test was carried out as described earlier by Bovee et al. 1998. An aliquot of $2130.5 \mathrm{~g}$ fat was mixed with hexane and extracted on acid silica as described previously. In each 214 test series a blanc butter fat sample and butter fat samples containing 1, 2, 3 and 6 pg TEQ/g 215 fat were included. The response obtained with the butter fat sample of $3 \mathrm{pg}$ TEQ/g, containing $2161.5 \mathrm{pg}$ TEQ/g dioxins and $1.5 \mathrm{pg}$ TEQ/g non-ortho PCBs, was used as the reference signal. 
217 Samples showing a lower response were declared negative, samples showing a higher 218 response suspected.

219 Aliquots of 5 gram feed or binder were mixed with $15 \mathrm{ml}$ methanol/water 85/15 (v/v) and 220 extracted twice with $20 \mathrm{ml}$ hexane/diethyl ether $97 / 3(\mathrm{v} / \mathrm{v})$. The extract was reduced to $5 \mathrm{ml}$ 221 and purified over acid silica columns as described above. Feed samples were included as 222 control samples. 


\section{Results and Discussion}

\section{Carry-over from feed to eggs (study I)}

\section{Dioxin and PCB levels in the feeds}

228 Table 2 shows the total levels of dioxins, dioxin-like PCBs and indicator PCBs in the various 229 feeds. Each feed was analysed 3 to 5 times, corresponding to the number of samples taken 230 from the different bags. The variation coefficients were in general below 5\%, demonstrating

231 the good homogeneity of the feeds. The relative contribution of dioxins, non-ortho and mono232 PCBs to the total TEQ level was as intended, being respectively 50,30 and $20 \%$. Table 3 233 shows the levels of the various congeners in the two highest contaminated feeds. The overall 234 levels were higher than intended, which cannot be explained by the background levels in the 235 feed ingredients, as shown by the level in the blank feed (A). However, since a rather broad 236 range of different concentrations in feed was used, this deviation had no consequences for the 237 aim of the study.

239 Levels in eggs

240 Table 4 shows the average feed consumption and the productivity of the hens, both during and

241 after the exposure period. There was no effect of the treatment on these parameters. The 242 exposure did not affect the average egg weight, but in all groups a slight decrease was 243 observed after 3.5 weeks on clean feed, resulting in weights around 48-51 grams per egg 244 (without shell). There is no explanation for this decrease, or possible consequences for the 245 residue levels in the eggs.

246 Figure 1 presents the time-related levels of dioxins (A), non-ortho PCBs (B), mono-ortho 247 PCBs (C) and total TEQ (D) in the eggs from the different exposure groups. These data show 
248 that even after 56 days on contaminated feed, levels in eggs continued to increase. In a similar 249 study, Pirard and De Pauw (2005) exposed laying hens to a dioxin level ten-fold higher than 250 our highest concentration. They observed a continuous increase in the levels for 4 weeks, at 251 which time point the animals stopped laying eggs. As shown in Figure 1, after cessation of the 252 exposure, there was initially a small increase in the residues, than a rapid decline, and 253 subsequently a much slower decrease. A similar profile was observed previously in a study 254 with much higher dioxin and PCB levels (Hoogenboom et al. 2002). The explanation lies in 255 the fact that the production of a full-grown yolk requires about ten days. Thus yolks of eggs 256 laid during the first days on clean feed were largely formed and contaminated during the 257 exposure period. Redistribution of dioxins from abdominal fat to the general circulation and 258 thus to eggs, may explain the slow decrease in residues during the latter part of the study. 259 Figure $1 \mathrm{~A}$ also shows that the current limit for eggs of $3 \mathrm{pg} \mathrm{TEQ} / \mathrm{g}$ fat was rapidly exceeded, 260 when exposed to feed containing dioxins just above the current limit for feed of $0.75 \mathrm{ng}$ $261 \mathrm{TEQ} / \mathrm{kg}$.

262 Figure 2 shows the levels of the 7 indicator PCBs in egg fat during the exposure and 263 depletion period. In general the pattern was very similar to that of the dioxins and dioxin-like 264 PCBs. Again, data indicate that egg levels continued to increase even after 56 days. At similar 265 dose levels (1.8 or $6 \mu \mathrm{g} / \mathrm{kg}$ feed), De Vos et al. (2005) observed steady-state levels after 266 respectively 40 or 70 days. The highest level obtained at 56 days of exposure via the most 267 contaminated feed was around $325 \mathrm{ng} / \mathrm{g}$ fat. Based on $4 \%$ fat in the feed, the feeds $\mathrm{E}$ and $\mathrm{F}$ 268 would contain respectively 350 and $800 \mathrm{ng} / \mathrm{g}$ fat, thereby exceeding e.g. the Belgium limit for 269 feed of $200 \mathrm{ng} / \mathrm{g}$. Only eggs from hens fed the highest contaminated feed F would actually 270 exceed the Belgium limit for indicator PCBs of $200 \mathrm{ng} / \mathrm{g}$ fat, although it cannot be excluded 271 that after longer exposure also eggs from hens fed with feed E might have approached the 272 limit. 
273 The relationship between the dioxin levels in feed and eggs after different periods of 274 exposure is graphically presented in Figure 3. There is a clear linear relationship between the 275 feed levels and the levels in eggs at the different exposure times. This figure also clearly 276 demonstrates that even after a short period on feed contaminated at the current EU-limit of $2770.75 \mathrm{ng}$ TEQ/kg, the limit for eggs was exceeded.

Levels in abdominal and ovary fat

280 The time-related levels of the sum of dioxins and dioxin-like PCBs (A), as well as the 7 281 indicator PCBs (B) in egg, abdominal and ovary fat sampled from the chickens fed with feed 282 E are shown in Figure 4. During the 56-days exposure period, levels in eggs and ovary fat 283 were comparable and generally higher than in the abdominal fat. This was particularly true for 284 the indicator PCBs. This difference was also clear for either dioxins or dl-PCBs (data not 285 shown). After another 56 days on clean feed, levels of dioxin-like compounds were very 286 similar in ovary and egg fat and slightly lower than in the abdominal fat. However, levels of 287 the indicator PCBs were clearly elevated in the abdominal fat. The combined results indicate 288 that the decrease of dioxins and PCBs is much slower in the body fat than in the eggs and 289 related ovaries. From the model for carry-over (Van Eijkeren et al.) it appears that the levels 290 in eggs possess a clearly bi-phasic nature, an initial phase with fast rising or, after cessation of 291 contamination, fast declining levels, followed by a terminal phase with slowly increasing or 292 decreasing levels. On the other hand, in abdominal fat, which acts as a great capacitor for 293 these highly lipophilic compounds, the relative contribution of the fast rising phase is very 294 low and the kinetics of contamination is almost mono-exponential with the rate of the slow 295 terminal phase 
297

298

299

300

301

302

303

304

305

306

307

308

309

310

311

312

313

314

315

316

317

318

319

320

321

\section{Carry-over rates of individual congeners from feed to egg}

To compare the carry-over of individual congeners from feed to eggs, it is possible to calculate the so-called Carry-Over Rate (COR), defined as the fraction of a certain congener excreted in the eggs, in relation to the amount ingested from the feed. Ideally, this should be done under steady-state conditions, but this was not achieved within the current study period. Therefore, the COR values should be regarded as minimum values. Based on the daily egg fat production of $5.1 \mathrm{~g}$ and daily feed intake of $116 \mathrm{~g}$, CORs were calculated for feeds $\mathrm{E}$ and $\mathrm{F}$ in I (Table 3). These data suggest a COR for the more important lower chlorinated congeners around $40 \%$ and a lower COR for the higher chlorinated hepta and octa congeners. This is in line with the observation by Pirard and De Pauw (2005) who also showed a much higher excretion of the higher chlorinated PCDD/Fs into the feces. The non-ortho and mono-ortho PCBs showed similar CORs as the lower chlorinated dioxins although some mono-ortho PCB congeners appeared to have even higher CORs. These were present at relatively low concentrations and in practice do not contribute significantly to the TEQ levels. In the group of the indicator PCBs, the lower chlorinated PCBs 53 and 101 showed very low carry-over rates, contrary to PCB 28. Similar has been observed previously in laying hens (De Vos et al. 2005) and broilers (Hoogenboom et al. 2004b, Maervoet et al. 2004). Based on excretion in the feces, De Vos et al. (2005) showed that active metabolism of these congeners must underly this observation.

Before steady state conditions are reached, part of the absorbed compounds are still accumulated in the body fat. Based on the mathematical modelling it is expected that after reaching steady-state, COR values will be doubled, implying that the amounts excreted in the eggs will be close to the amounts ingested (Van Eijkeren et al. 2005). As for total TEQ levels, the absorbed fraction ranges between $90 \%$ and $100 \%$, the COR for total TEQs at steady state is expected to range between the same limits. 


\section{Carry-over from soil to eggs (study II)}

324 Table 5 shows the levels of dioxins and PCBs in feed E, feed E mixed with $10 \%$ sand and the

two blank feeds mixed with $10 \%$ of the soils sampled at two chicken farms. The two soils 326 were reanalysed and shown to contain respectively 4.0 and $1.7 \mathrm{ng}$ TEQ dioxins per $\mathrm{kg}$ and 327 only minor amounts of dioxin-like PCBs. The level in the feed containing soil A is in 328 agreement with the dilution, the level in the feed with soil B is relatively high which can best 329 be explained by the application of the upperbound principle. Lower bound levels (i.e. levels 330 of non-detects set at 0 ) in these two feeds were respectively 0.40 and $0.19 \mathrm{ng} \mathrm{TEQ} / \mathrm{kg}$, 331 reflecting the differences observed in the soil.

332 Figure 5 shows the dioxin and dioxin-like PCB levels in the eggs from the hens 333 obtaining these feeds. Time-related levels in the eggs from the hens fed with feed E, either 334 without or with $10 \%$ sand were very similar to the results obtained in study I. The dilution of 335 contaminated feed with $10 \%$ sand did not clearly influence the levels observed in the eggs and 336 abdominal fat. The results obtained with the blank feed mixed with $10 \%$ soil A or soil B 337 reflected the differences in the soil and feed levels. A plateau level appeared to be reached in 338 this study within a short period of exposure. Maximum dioxin and total TEQ levels measured 339 in eggs from hens exposed to soil A were 2.4 and $2.9 \mathrm{pg} \mathrm{TEQ} / \mathrm{g}$ fat. In the case of soil B, 340 highest levels of 1.2 and $1.6 \mathrm{pg}$ TEQ/g were observed. Again, levels in abdominal fat were 341 lower than those for egg fat (data not shown). For comparison, levels determined in pooled 342 egg samples from the farms where the soil was sampled were 7.3 and $1.0 \mathrm{pg} \mathrm{TEQ} / \mathrm{g}$ fat.

344 Effect of binders (study III)

345 Table 5 includes the levels of dioxins and PCBs in the four feeds supplemented with the 346 different binders. Levels in egg and abdominal fat of the hens fed with these feeds showed 
347 that the binders, at least at the levels used in this study, had little or no effect on the residue 348 levels of dioxins and PCBs in the eggs (Table 6), although in the case of MycoAd AZ and 349 especially Klinofeed, both aluminium silicates, there appeared to be a slight decrease in the 350 levels of the different contaminants in both the eggs and the abdominal fat. It seems 351 worthwhile to investigate if higher levels may have a more profound effect, and whether this 352 also works with the absorption of dioxins and PCBs from soil..

353

354

355

356

357

358

359

360

361

362

363

364

365

366

367

\section{Conclusions}

- Laying hens are sensitive indicators for dioxin exposure, meaning that relatively low intake levels result in high levels in the egg yolk. This is not only true for contaminated feed but also for contaminated soil.

- The current EU limit for feed of $0.75 \mathrm{ng} \mathrm{TEQ} / \mathrm{kg}$, established in 2002, is insufficient to guarantee that levels in eggs will not exceed the limit of $3 \mathrm{ng} T E Q / \mathrm{kg}$ fat. A further decrease in the feed limit by a factor 4 is required to achieve this goal. The alternative is to increase the limit in eggs, but this is not in line with the further reduction in the exposure aimed at by the EU authorities.

- There are currently no Dutch or European limits for indicator PCBs in feed or eggs. However, the Belgium limit of $200 \mathrm{ng} / \mathrm{g}$ fat for feed does ensure that the limit for eggs of $200 \mathrm{ng} / \mathrm{g}$ fat is not exceeded.

- Addition of binders at the tested levels has minimal effects on the resulting residues of dioxins and PCBs in hens.

\section{Acknowledgements}

The study was sponsored by the Dutch Ministry of Agriculture, Nature and Food Quality. 
372

373

374

375

376

377

378

379

380

381

382

383

384

385

386

387

388

389

390

391

392

393

394

395

396

397

398

399

400

401

402

403

404

405

406

407

408

409

410

411

412

413

414

415

416

417

418

419

420

\section{References}

Air V, Pless-Mulloli T, Schilling B, Paepke O, Foster K. 2002. Follow-up assessment of PCDD/PCDF in eggs from allotments in Newcastle upon Tyne, England, Organohalogen Compounds 57: 237-240.

Bovee TFH, Hoogenboom LAP, Hamers ARM, Aarts JMMJG, Brouwer A, Kuiper HA. 1998. Validation and use of the CALUX-bioassay for the detection of dioxins and coplanar PCBs in bovine milk. Food Additives and Contaminants 15: 863-875.

Brandsma EM, Binnendijk GP, De Buisonjé FE, Mul MF, Bokma-Bakker MH, Hoogenboom LAP, Traag WA, Kan CA, De Bree J, Kijlstra A. 2004. Onderzoek naar factoren die het dioxinegehalte in biologische eieren kunnen beïnvloeden, Praktijkrapport Pluimveehouderij nr. 1330386003, ASG, Lelystad.

De Vries J. 2002. Monitoring dioxine-gehalte in eieren afkomstig van biologische legbedrijven. Rapport Keuringsdienst van Waren OT O105A.

De Vos S, Verschueren D, De Schrijver R. 2005. Digestibility, retention and incorporation of low-level dietary PCB content in laying hens. Chemosphere 58: 1552-1562.

EC. 2001. Council regulation (EC) No 2375/2001 of 29 November 2001 amending Commission Regulation (EC) No 466/2001 setting maximum levels for certain contaminants in foodstuffs, Official Journal of the European Communities L321: 1-5.

EC. 2002. Council directive 2001/102/EC of 27 November 2001 amending Directive a999/29/EC on the undesirable substances and products in animal nutrition, Official Journal of the European Communities L6: 45-49.

Harnly ME, Petreas MX, Flattery J, Goldman LR. 2000. Polychlorinated dibenzo-p-dioxin and polychlorinated dibenzofuran contamination in soil and home-produced chicken eggs near pentachlorophenol sources, Environmental Science and Technology 34: 1143-1149.

Hoogenboom LAP, Traag WA, Kan CA, Bovee TFH, Van der Weg G, Onstenk C, Portier L. 2002. Residues of dioxins and PCBs in eggs following short-term exposure of laying hens to feed from the Belgian crisis, Organohalogen Compounds 57: 241-244.

Hoogenboom LAP. 2004. Behaviour of polyhalogenated and polycyclic aromatic hydrocarbons in food-producing animals. In Annual Reviews in Food and Nutrition; Toxic and Pathological Aspects, Eds Preedy V.R. and Watson R.R., Taylor and Francis, London. aanvullen.

Hoogenboom LAP, Kan CA, Bovee TFH, Van der Weg G, Onstenk C, Traag WA. 2004. Residues of dioxins and indicator PCBs in fat of growing pigs and broilers, Chemosphere 57: 35-42.

Lovett AA, Foxall CD, Creaser CS, Chewe D. 1998. PCB and PCDD/DF concentrations in egg and poultry meat samples from known urban and rural locations in Wales and England. Chemosphere 37: 1671-1685. 
Maervoet J, Chu SG, De Vos S, Covaci A, Voorspoels S, De Schrijver R, Schepens P. 2004. Accumulation and tissue distribution of selected polychlorinated biphenyl congeners in chickens, Chemosphere 57: 61-66.

Petreas MX, Goldman LR, Hayward DG, Chang RR, Flattery JJ, Wiesmüller T, Stephens RD. 1991. Biotransfer and bioaccumulation of PCDD/PCDFs from soil: Controlled exposure studies of chickens. Chemosphere 2: 1731-1741.

Pirard C, De Pauw E. 2005. Uptake of polychlorodibenzo-p-dioxins, polychlorodibenzofurans and coplanar polychlorobiphenyls in chickens. Environment International 31: 585-591.

Pussemier L, Mohimont L, Huyghebaert A, Goeyens L. 2004. Enhanced levels of dioxins in eggs from free range hens; a fast evaluation approach. Talanta 63: 1273-1276.

SCF, 2001, Opinion of the Scientific Committee on Food on the risk assessment of dioxins and dioxin-like PCBs in food. Scientific Committee on Food report CS/CNTM/DIOXIN/20 final. http://europa.eu.int/comm/food/fs/sc/scf/out90_en.pdf.

Schuler F, Schmid P, Schlatter Ch. 1997. The transfer of polychlorinated dibenzo-p-dioxins and dibenzofurans from soil into eggs of foraging chicken. Chemosphere 34: 711-718.

Stephens RD, Harnly M, Hayward DG, Chang RR, Flattery J, Petreas MX, Goldman L. 1990. Bioaccumulation of dioxins in food animals II: Controlled exposure studies. Chemosphere 20: 1091-1096.

Stephens RD, Petreas MX, Hayward DG. 1994. Absorption, distribution and elimination of all 2,3,7,8-substituted PCDD/PCDFs resulting from chronic exposure of chickens to ppt level contamination in soil. Organohalogen Compounds 20: 55-58.

Stephens RD, Petreas MX, Hayward DG. 1995. Biotransfer and bioaccumulation of dioxins and furans from soil: Chickens as a model fro foraging animals. Science of the Total Environment. 175: 253-273.

Traag WA, Portier L, Bovee TFH, Van der Weg G, Onstenk C, Elghouch N, Coors R, Van de Kraats C, Hoogenboom LAP. 2002. Residues of dioxins and coplanar PCBs in eggs of free range chickens, Organohalogen Compounds 57: 245-248.

Tuinstra LGMTh, Traag WA, Van Rhijn JA, Van de Spreng PF. 1994. The Dutch PCB/dioxin study: development of a method for the determination of dioxins, planar and other PCBs in human milk. Chemosphere 29: 1859-1875.

Van den Berg, M , Birnbaum LS, Bosveld ATC, Brunström B, Cook Ph, Feeley M, Giesy JP, Hanberg A, Hasegawa R, Kennedy SW, Kubiak T, Larsen JC, Leeuwen FXR van, Liem AKD, Nolt C, Peterson RE, Poellinger L, Safe S, Schrenk D, Tillitt D, Tysklind M, Younes M, Wärn F. Zacharewski T. 1998. Toxic Equivalency Factors (TEFs) for PCBs, PCDDs, PCDFs for humans and wildlife. Environmental Health Perspectives 106: 775792. 
469 Van Eijkeren JCH, Zeilmaker MJ, Kan CA, Traag WA, Hoogenboom LAP. A PB-PK based 470 model for the carry-over of dioxins and PCBs from feed and soil to eggs. Food Additives 471 and Contaminants (submitted). 


\section{Legends}

473

474 Figure 1. Levels of dioxins (A), non-ortho PCBs (B), mono-ortho PCBs (C) and total TEQ

475 (D) in egg fat from hens fed with feeds containing $0.04(\mathrm{~A},+), 0.34(\mathrm{~B}, \Delta$, open triangle), 0.58

$476(\mathrm{C}, \boldsymbol{\Delta}$, closed triangle), $0.76(\mathrm{D}$, , , open circle), 1.85 (E, $\diamond$, open diamond) and $3.95(\mathrm{~F}, \boldsymbol{\nabla}$, 477 reversed triangles) ng TEQ/kg of dioxins and PCBs.

478

479 Figure 2. Levels of indicator PCBs in egg fat from hens fed with feeds containing $0.2(\mathrm{~A},+)$,

$4802.3(\mathrm{~B}, \Delta$, open triangle $), 4.3(\mathrm{C}, \boldsymbol{\Delta}$, closed triangle $), 6.0(\mathrm{D}$, , , open circle $), 14.2(\mathrm{E}, \diamond$, open 481 diamond) and 31.7 (F, $\nabla$, reversed triangles) $\mu \mathrm{g} / \mathrm{kg}$ feed of indicator PCBs. 482

483 Figure 3. Relation between dioxin levels in feed and egg fat after 10 ( $\boldsymbol{\nabla}$, reversed triangles), 48432 ( $\boldsymbol{\Lambda}$, closed triangle) and 58 ( $\bullet$, closed circle) days of feeding contaminated feed. Solid 485 lines represent the current limits in feed and eggs, dashed lines the action limits in the EU. 486

487 Figure 4. Levels of dioxins and dioxin-like PCBs (A), and indicator PCBs in egg ( $\boldsymbol{\Delta}$, closed 488 triangle), abdominal ( $\boldsymbol{\nabla}$, reversed triangles) and ovary fat $(\bullet$, closed circle $)$ from chickens fed 489 with feed E.

490

491 Figure 5. Levels of dioxins (A) and total TEQ (B) in egg fat from hens fed with feed $750(\bullet$, 492 closed circle), feed 750 mixed with $10 \%$ sand ( $\boldsymbol{\Delta}$, closed triangle), and blank feed mixed with $49310 \%$ soil A ( $\bullet$, closed diamond) or soil B ( $\boldsymbol{\square}$, closed square). For comparison the results 494 obtained with feed 750 in the first study are included (०, open circle). 
1

4

5

6

7

8

9

10

11

12

13

14

15

16

17

18

19

20

21

22

23

24

25

26

27

28

29

30

31

32

33

34

35

36

37

38

39

40

41

42

43

44

45

46

47

48

49

50

51

52

53

54

55

56

57

58

59

60

495 Table 1 shows the ingredients of the feed, Topline extra.

496

\begin{tabular}{lc}
\hline Ingredient & Amount $(\%)$ \\
\hline Corn & 32.53 \\
Wheat & 19.61 \\
Corn-by-products & 2.00 \\
Maizeglutenfeed & 3.52 \\
Wheatglutenfeed & 4.31 \\
Soybeans, extracted & 13.98 \\
Sunflower seed, extracted & 7.42 \\
Rape seed extracted & 2.33 \\
Limestone fine <15 mm & 2.00 \\
Limestone 1-3 mm & 7.55 \\
Monocalcium phosphate & 0.06 \\
Sodium chloride & 0.16 \\
Sodium carbonate & 0.12 \\
Chicken fat & 4.00 \\
Methionin 98 & 0.09 \\
Fytase 5000 L & 0.01 \\
Cholinchloride & 0.02 \\
Fish oil & 0.10 \\
Vitamin mix 44 & 0.30 \\
\hline
\end{tabular}

497 
498 Table 2. Levels of dioxins, non-ortho, mono-ortho and indicator PCBs in the different feeds used in 499 study I, as determined by GC/MS. Results are expressed as upperbound* levels and are the mean of 35005 analyses. The \% CV of the TEQ levels is given in brackets.

501

\begin{tabular}{cccccc}
\hline Feed & Dioxins & no-PCBs & mo-PCBs & total TEQ & $\begin{array}{c}\text { Indicator } \\
\text { PCBs } \\
\end{array}$ \\
& $($ ng TEQ $/ \mathrm{kg})$ & $(\mathrm{ng} \mathrm{TEQ} / \mathrm{kg})$ & $(\mathrm{ng} \mathrm{TEQ} / \mathrm{kg})$ & $(\mathrm{ng} \mathrm{TEQ} / \mathrm{kg})$ & $(\mu \mathrm{g} / \mathrm{kg})$ \\
\hline
\end{tabular}

\begin{tabular}{llllll}
\hline & & & & & \\
A & $0.04(10)$ & $0.00(16)$ & $0.00(3)$ & $0.04(10)$ & $0.2(14)$ \\
B & $0.20(18)$ & $0.09(4)$ & $0.06(4)$ & $0.34(12)$ & $2.3(1)$ \\
C & $0.30(2)$ & $0.17(3)$ & $0.11(1)$ & $0.58(2)$ & $4.3(7)$ \\
D & $0.40(2)$ & $0.22(2)$ & $0.14(1)$ & $0.76(1)$ & $6.0(4)$ \\
E & $0.97(1)$ & $0.55(2)$ & $0.33(1)$ & $1.85(1)$ & $14.2(2)$ \\
F & $2.04(2)$ & $1.19(1)$ & $0.72(2)$ & $3.95(1)$ & $31.7(3)$ \\
\hline
\end{tabular}

* only in the case of feed A, lowerbound differed from upperbound levels, being respectively 0.01 and $0.02 \mathrm{ng} \mathrm{TEQ} / \mathrm{kg}$ for dioxins and total TEQ. 
505 Table 3. Levels of the different dioxin and PCB congeners in feeds E and F and the eggs from 506 chickens fed with these feeds and sampled at day 56. Feed was analyzed in five-fold, eggs once. Based 507 on feed intake and egg production, carry-over rates for feed to eggs were determined for day 56.

508

\begin{tabular}{lcccccc}
\hline & feed E & $\begin{array}{c}\text { eggs E } \\
\text { day } 56\end{array}$ & $\begin{array}{c}\text { carry-over } \\
(\%)\end{array}$ & feed F & $\begin{array}{c}\text { eggs F } \\
\text { day } 56\end{array}$ & $\begin{array}{c}\text { carry-over } \\
(\%)\end{array}$ \\
\hline dioxins & ng/kg & pg/g fat & & ng/kg & pg/g fat & \\
$2,3,7,8-$-TCDF & 0.12 & 1.10 & 40 & 0.25 & 2.33 & 40 \\
$1,2,3,7,8-P e C D F$ & 0.33 & 2.86 & 39 & 0.66 & 7.15 & 48 \\
$2,3,4,7,8-P e C D F$ & 0.33 & 2.83 & 38 & 0.67 & 6.76 & 44 \\
$1,2,3,4,7,8-H x C D F$ & 0.34 & 3.33 & 43 & 0.70 & 7.00 & 44 \\
$1,2,3,6,7,8-H x C D F$ & 0.33 & 2.98 & 40 & 0.68 & 6.44 & 42 \\
$2,3,4,6,7,8-H x C D F$ & 0.43 & 3.03 & 31 & 0.84 & 6.80 & 35 \\
$1,2,3,7,8,9-H x C D F$ & 0.32 & 2.85 & 39 & 0.67 & 6.28 & 41 \\
$1,2,3,4,6,7,8-H p C D F$ & 0.40 & 1.60 & 18 & 0.82 & 3.26 & 18 \\
$1,2,3,4,7,8,9-H p C D F$ & 0.32 & 1.44 & 20 & 0.66 & 3.06 & 21 \\
OCDF & 0.63 & 0.98 & 7 & 1.39 & 1.55 & 5 \\
2,3,7,8-TCDD & 0.14 & 1.31 & 41 & 0.30 & 3.26 & 47 \\
$1,2,3,7,8-P e C D D$ & 0.37 & 3.39 & 41 & 0.79 & 8.04 & 45 \\
$1,2,3,4,7,8-H x C D D$ & 0.40 & 3.80 & 42 & 0.84 & 8.38 & 44 \\
$1,2,3,6,7,8-H x C D D$ & 0.35 & 3.45 & 44 & 0.74 & 7.49 & 44 \\
$1,2,3,7,8,9-H x C D D$ & 0.40 & 2.87 & 32 & 0.84 & 6.49 & 34 \\
$1,2,3,4,6,7,8-H p C D D$ & 0.42 & 2.15 & 22 & 0.84 & 3.97 & 21 \\
OCDD & 1.34 & 3.82 & 13 & 2.57 & 4.78 & 8 \\
\hline non-ortho-PCBs & ng/kg & pg/g fat & & ng/kg & pg/g fat & \\
PCB 81 & 5.12 & 46.70 & 40 & 10.86 & 102.0 & 41 \\
PCB 77 & 10.85 & 112.00 & 45 & 22.06 & 252.0 & 50 \\
PCB 126 & 4.98 & 54.10 & 48 & 10.86 & 123.0 & 50 \\
PCB 169 & 4.89 & 55.40 & 50 & 10.55 & 124.0 & 52 \\
\hline mono-ortho PCBs & ng/kg & ng/g fat & & ng/kg & ng/g fat & \\
PCB 123 & 5 & 0.10 & 78 & 14 & 0.22 & 70 \\
PCB 118 & 1576 & 17.10 & 48 & 3454 & 40.60 & 52 \\
PCB 114 & 6 & 0.07 & 52 & 14 & 0.16 & 51 \\
PCB 105 & 894 & 9.36 & 46 & 1940 & 23.00 & 52 \\
PCB 167 & 10 & 0.20 & 84 & 24 & 0.41 & 76 \\
PCB 156 & 139 & 1.75 & 55 & 307 & 4.03 & 58 \\
PCB 157 & 13 & 0.15 & 51 & 26 & 0.39 & 65 \\
PCB 189 & 10 & 0.14 & 61 & 21 & 0.29 & 61 \\
\hline indicator-PCBs & $\mu \mathrm{g} / \mathrm{kg}$ & ng/g fat & & $\mu \mathrm{g} / \mathrm{kg}$ & ng/g fat & \\
PCB 28 & 0.98 & 8.4 & 38 & 2.13 & 20.7 & 43 \\
PCB 52 & 1.30 & 1.6 & 5 & 2.91 & 2.9 & 4 \\
PCB 101 & 2.88 & 3.5 & 5 & 6.33 & 7.5 & 5 \\
PCB 138 & 2.99 & 34.6 & 51 & 6.72 & 83.1 & 54 \\
PCB 153 & 2.79 & 36.1 & 57 & 6.27 & 86.2 & 61 \\
PCB 180 & 1.89 & 25.6 & 59 & 4.27 & 58.5 & 41 \\
\hline
\end{tabular}


510 Table 4. Feed consumption and productivity of the hens during and after the exposure period. Data are 511 based on the overall feed consumption and egg production over the whole exposure or withdrawal 512 period.

513

\begin{tabular}{ccccccc}
\hline Feed & $\begin{array}{c}\text { Feed } \\
\text { consumption } \\
(\mathrm{g} / \text { day })\end{array}$ & $\begin{array}{c}\text { Exposure period } \\
\text { Egg } \\
\text { production } \\
(\%)\end{array}$ & $\begin{array}{c}\text { Egg weight* } \\
(\mathrm{g})\end{array}$ & $\begin{array}{c}\text { Feed } \\
\text { consumption } \\
(\mathrm{g} / \text { day })\end{array}$ & $\begin{array}{c}\text { Withdrawal period } \\
\text { production } \\
(\%)\end{array}$ & $\begin{array}{c}\text { Egg weight* } \\
(\mathrm{g})\end{array}$ \\
\hline $\mathrm{A}$ & 116 & 88 & 54 & 112 & 85 & 50 \\
$\mathrm{~B}$ & 108 & 82 & 56 & 111 & 86 & 51 \\
$\mathrm{C}$ & 121 & 90 & 56 & 121 & 84 & 53 \\
$\mathrm{D}$ & 113 & 80 & 55 & 110 & 86 & 52 \\
$\mathrm{E}$ & 124 & 90 & 54 & 121 & 84 & 51 \\
$\mathrm{~F}$ & 108 & 90 & 54 & 111 & 79 & 51 \\
\hline
\end{tabular}

$514 *$ average weight per egg without eggshell 
1

519

\section{5}

516 Table 5. Levels of dioxins, non-ortho and mono-ortho PCBs in the different feeds used in studies II

517 and III, as determined by GC/HRMS (mean of $n=5$, upperbound levels, lowerbound between brackets

518 where different from upperbound).

\begin{tabular}{clcll}
\hline Feed & $\begin{array}{c}\text { Dioxins } \\
(\text { ng TEQ/kg) }\end{array}$ & $\begin{array}{c}\text { no-PCBs } \\
(\text { ng TEQ/kg) }\end{array}$ & $\begin{array}{c}\text { mo-PCBs } \\
(\text { ng TEQ/kg) }\end{array}$ & $\begin{array}{c}\text { total TEQ } \\
(\text { ng TEQ/kg) }\end{array}$ \\
\hline E & 0.73 & 0.43 & 0.27 & 1.41 \\
E + 10\% sand & 0.65 & 0.39 & 0.25 & 1.28 \\
$\mathrm{~A}+10 \%$ soil A & $0.44(0.40)$ & 0.10 & $0.05(0.04)$ & $0.64(0.53)$ \\
A + 10\% soil B & $0.35(0.19)$ & 0.11 & $0.08(0.07)$ & $0.54(0.37)$ \\
& & & & \\
E + Exal H & 0.87 & 0.53 & 0.33 & 1.73 \\
E + MycoAd Z & 0.93 & 0.55 & 0.34 & 1.81 \\
E + Klinofeed & 0.84 & 0.51 & 0.34 & 1.70 \\
& & & & \\
\hline
\end{tabular}


521 Table 6. Levels of dioxins, non-ortho, mono-ortho and indicator PCBs in the eggs and abdominal fat 522 of chickens exposed in the absence or presence of mycotoxin binders. Samples collected at day 32 523 were pooled from 5 hens or eggs and analyzed in single.

524

\begin{tabular}{lccccc}
\hline Feed & Dioxins & no-PCBs & mo-PCBs & total TEQ & $\begin{array}{c}\text { Indicator } \\
\text { PCBs } \\
\text { ng/g fat }\end{array}$ \\
\hline Eggs & pg TEQ/g) & $(\mathrm{pg} \mathrm{TEQ/g)}$ & $(\mathrm{pg} \mathrm{TEQ/g})$ & $(\mathrm{pg} \mathrm{TEQ/g})$ & \\
Feed E & 7.4 & 5.3 & 3.1 & 15.8 & 117 \\
E + Exal H & 7.4 & 4.7 & 2.9 & 15.0 & 109 \\
E + MycoAd Z & 6.2 & 4.3 & 2.6 & 13.1 & 97 \\
E + Klinofeed & 6.8 & 4.3 & 2.6 & 13.7 & 100 \\
\hline Abdominal fat & & & & & \\
Feed E & 6.2 & 4.5 & 3.0 & 13.7 & 84 \\
E + Exal H & 5.7 & 4.3 & 2.9 & 12.9 & 89 \\
E + MycoAd Z & 5.4 & 4.0 & 2.6 & 11.9 & 81 \\
E + Klinofeed & 4.8 & 3.4 & 2.3 & 10.4 & 71 \\
& & & & & \\
\hline
\end{tabular}

\section{5}

526

527 

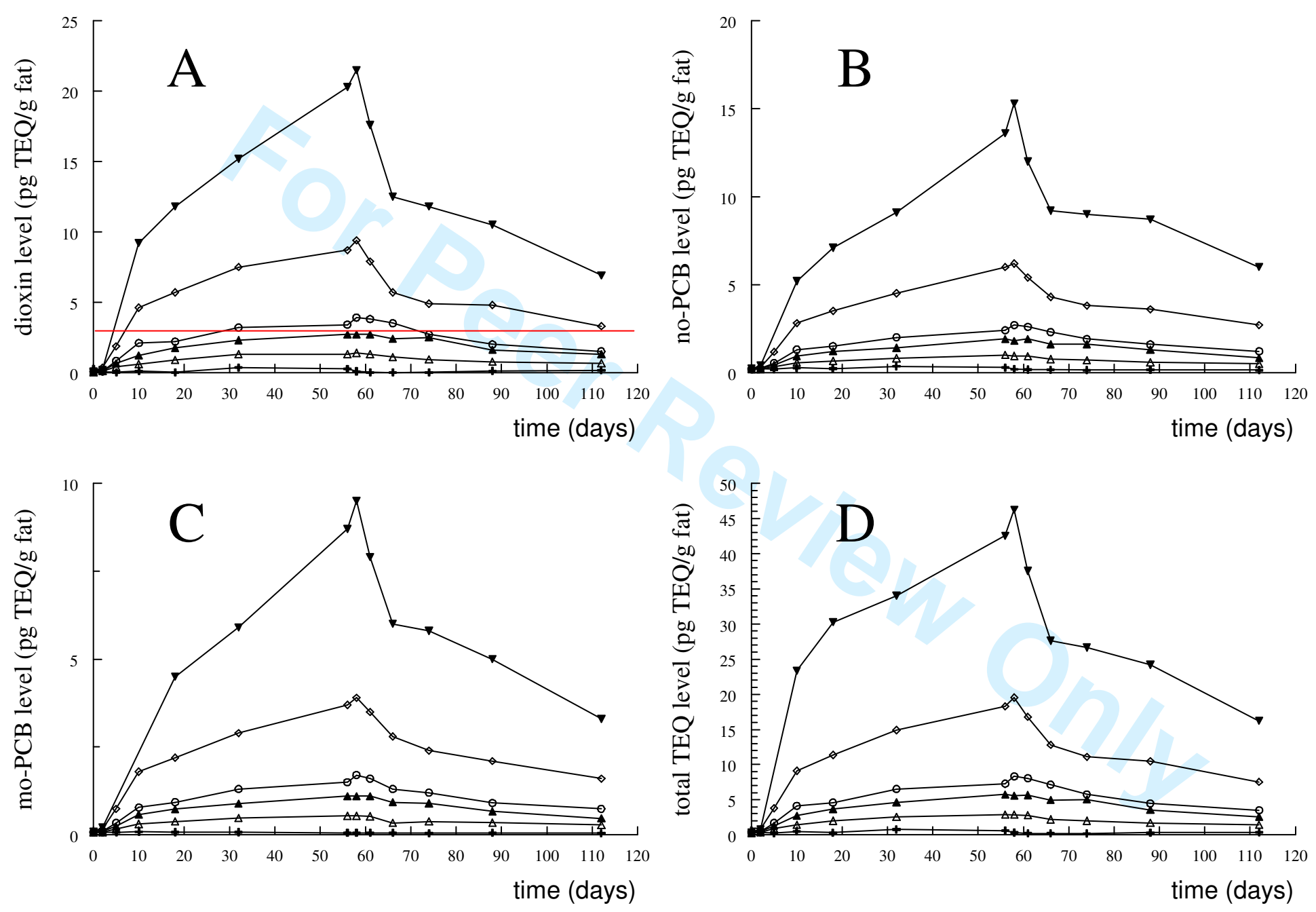

Figure 1. Levels of dioxins (A), non-ortho PCBs (B), mono-ortho PCBs (C) and total TEQ (D) in egg fat from hens fed with feeds containing 0.04 (A, +), 0.34 (B, $\Delta$, open triangle), $0.58(\mathrm{C}, \mathbf{\Delta}$, closed triangle), $0.76(\mathrm{D}, \circ$, open circle), 1.85 (E, $\diamond$, open diamond) and 3.95 (F, $\boldsymbol{\nabla}$, reversed triangles) ng TEQ/kg of dioxins and PCBs. Results from single analysis. 


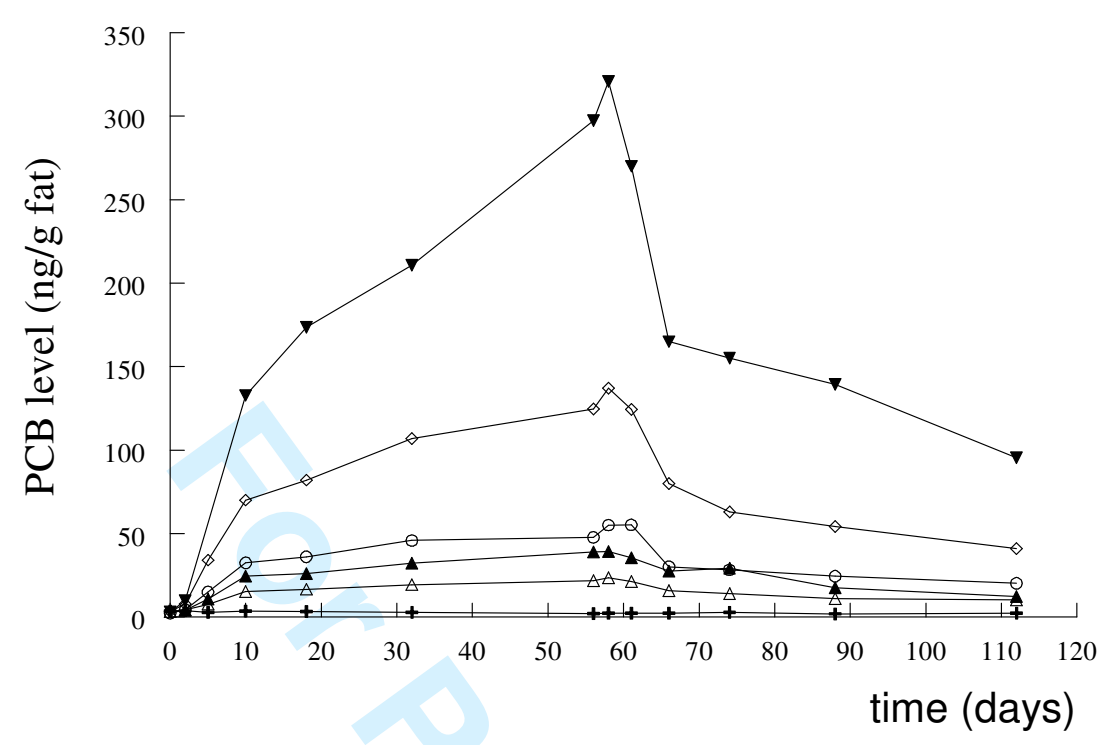

Figure 2. Levels of indicator PCBs in egg fat from hens fed with feeds containing $0.2(\mathrm{~A},+), 2.3(\mathrm{~B}, \Delta$, open triangle), 4.3 (C, $\mathbf{\Delta}$, closed triangle), 6.0 (D, o, open circle), 14.2 (E, $\diamond$, open diamond) and 31.7 $(\mathrm{F}, \boldsymbol{\nabla}$, reversed triangles) $\mu \mathrm{g} / \mathrm{kg}$ feed of indicator PCBs. Results from single analysis. 


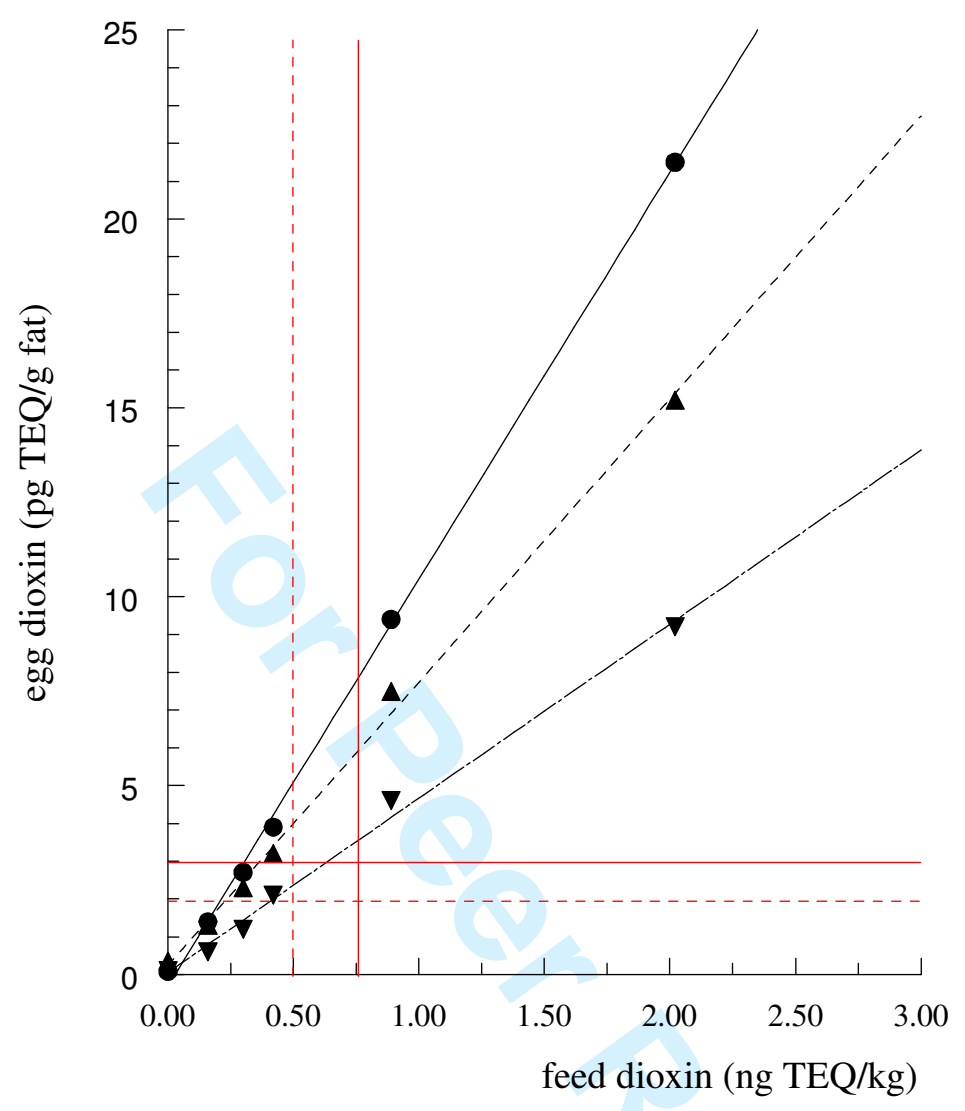

Figure 3. Relation between dioxin levels in feed and egg fat after 10 ( $\boldsymbol{\nabla}$, reversed triangles), 32 ( $\boldsymbol{\Lambda}$, closed triangle) and $58(\bullet$, closed circle) days of feeding contaminated feed. Solid lines represent the current limits in feed and eggs, dashed lines the action limits in the EU. 

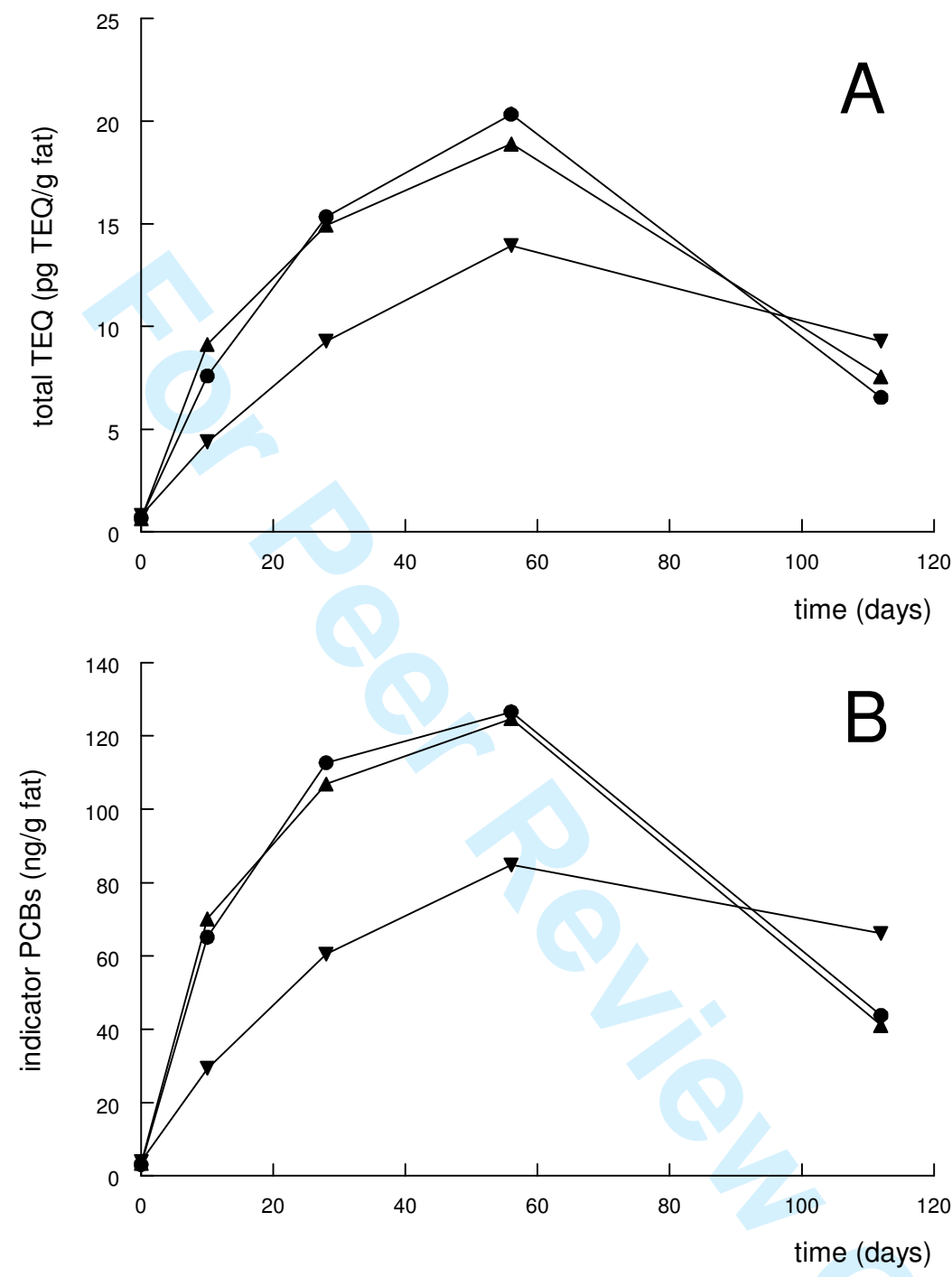

Figure 4. Levels of dioxins and dioxin-like PCBs (A), and indicator PCBs (B) in egg ( $\boldsymbol{\Delta}$, closed triangle), abdominal ( $\boldsymbol{\nabla}$, reversed triangles) and ovary fat $(\bullet$, closed circle) from chickens fed with feed E. Results from single analysis. 

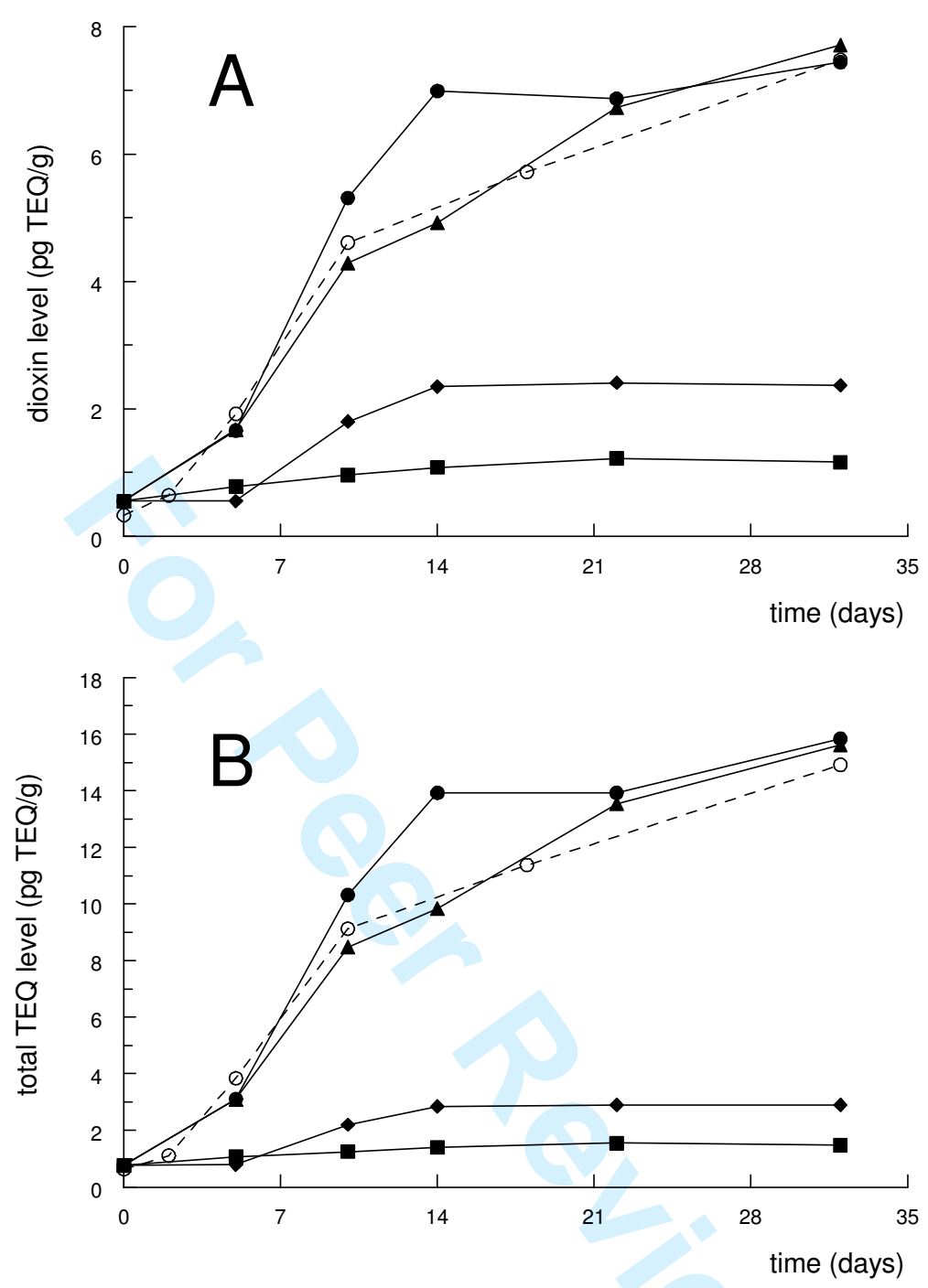

Figure 5. Levels of dioxins (A) and total TEQ (B) in egg fat from hens fed with feed E (•, closed circle), feed $\mathrm{E}$ mixed with $10 \%$ sand ( $\boldsymbol{\Lambda}$, closed triangle), and blank feed A mixed with $10 \%$ soil A ( closed diamond) or soil B ( $\boldsymbol{\square}$, closed square). For comparison the results obtained with feed $\mathrm{E}$ in the first study are included ( $\circ$, open circle). Results from single analysis. 